\title{
JOB-TO-JOB (J2J) FLOWS: NEW LABOR MARKET STATISTICS FROM LINKED EMPLOYER-EMPLOYEE DATA
}

\author{
by \\ Henry Hyatt \\ U.S. Census Bureau \\ Erika McEntarfer \\ U.S. Census Bureau \\ Kevin McKinney \\ U.S. Census Bureau \\ Stephen Tibbets \\ U.S. Census Bureau \\ Doug Walton \\ U.S. Census Bureau
}

CES 14-34 September, 2014

The research program of the Center for Economic Studies (CES) produces a wide range of economic analyses to improve the statistical programs of the U.S. Census Bureau. Many of these analyses take the form of CES research papers. The papers have not undergone the review accorded Census Bureau publications and no endorsement should be inferred. Any opinions and conclusions expressed herein are those of the author(s) and do not necessarily represent the views of the U.S. Census Bureau. All results have been reviewed to ensure that no confidential information is disclosed. Republication in whole or part must be cleared with the authors.

To obtain information about the series, see www.census.gov/ces or contact Fariha Kamal, Editor, Discussion Papers, U.S. Census Bureau, Center for Economic Studies 2K132B, 4600 Silver Hill Road, Washington, DC 20233, CES.Papers.List@census.gov. 


\begin{abstract}
Flows of workers across jobs are a principal mechanism by which labor markets allocate workers to optimize productivity. While these job flows are both large and economically important, they represent a significant gap in available economic statistics. A soon to be released data product from the U.S. Census Bureau will fill this gap. The Job-to-Job (J2J) flow statistics provide estimates of worker flows across jobs, across different geographic labor markets, by worker and firm characteristics, including direct job-to-job flows as well as job changes with intervening nonemployment. In this paper, we describe the creation of the public-use data product on job-tojob flows. The data underlying the statistics are the matched employer-employee data from the U.S. Census Bureau's Longitudinal Employer-Household Dynamics program. We describe definitional issues and the identification strategy for tracing worker movements between employers in administrative data. We then compare our data with related series and discuss similarities and differences. Lastly, we describe disclosure avoidance techniques for the public use file, and our methodology for estimating national statistics when there is partially missing geography.
\end{abstract}




\section{Introduction}

The Census Bureau plans to release this fall a beta version of a new set of national job-tojob flow statistics derived from the Longitudinal Employer-Household Dynamics (LEHD) infrastructure files. ${ }^{1}$ By linking matched employer-employee data over time, the LEHD program currently provides data on employment separations and accessions, job creation and job destruction, earnings and employment. Expanding that set of statistics to include flows across jobs exploits the ability in the LEHD data to link separations and accessions across employers. Unlike other available survey data sources such as the Current Population Survey (CPS), the LEHD administrative data is of sufficient size to provide public use statistics on these flows at detailed industry and geography levels.

In this paper, we describe definitional issues, and the identification strategy for tracing worker movements between employers in administrative data. We then show sample statistics from the current prototype of the J2J data and compare these to job-to-job flows with data on employment transition from the CPS as aggregated by Fallick and Fleischman (2004). In the last sections of the paper, we describe our disclosure avoidance techniques for the public use file, and the methodology for estimating national statistics when there is partially missing geography.

\footnotetext{
${ }^{1}$ For detailed description of the LEHD data, see Abowd et al. (2009) and Abowd, Haltiwanger, and Lane (2004).
} 


\section{The Data}

The data we describe in this paper are produced by the LEHD program at the U.S. Census Bureau. The LEHD data consist of quarterly worker-level earnings submitted by employers for the administration of state unemployment insurance (UI) benefit programs, linked to establishment-level data collected for the Quarterly Census of Employment and Wages (QCEW) program. As of this writing, all 50 states, DC, Puerto Rico, and the Virgin Islands share QCEW and UI wage data with the LEHD program as part of the Local Employment Dynamics federal-state partnership. LEHD data coverage is quite broad; state UI covers $95 \%$ of private sector employment, as well as state and local government. Demographic data come from survey, Census, and administrative record sources, see Abowd et al. (2009). The LEHD program recently linked data on national firm age and size from the Business Dynamics Statistics to LEHD establishments, see Haltiwanger et al. (2014).

The J2J flows data described here owes an intellectual debt to several earlier research papers linking workers across jobs in the LEHD data, along with earlier work by Fallick and Fleischman (2004) using the CPS. Bjelland et al. (2011) describe an early prototype of job-to-job flows using the LEHD data; they link beginning of quarter jobs in the LEHD data but do not identify nonemployment flows. Fallick, Haltiwanger, and McEntarfer (2012) and Hyatt and McEntarfer (2012a, 2012b) both traced main job transitions as well as flows to nonemployment. The J2J data to be released this fall are most similar to the tabulations described in Hyatt and McEntarfer (2012b), with some important methodological differences. The most substantive change from the early prototype described in that paper is that the released J2J flows will trace movements between dominant jobs, defined as the maximal earnings job among those held on the first day of each quarter (as opposed to dominant among any job held in the quarter). This change allows important identities to hold - particularly the ability to decompose employment changes into hires from employment vs. nonemployment. It does also reduce the number of marginally attached workers in the data by construction (i.e. they are less likely to hold jobs at a particular point in time); job-to-job flow rates are lower in consequence in the released version of J2J flows, compared with tabulations derived from this earlier database.

\section{Job-to-Job Flow Definitions}

The primary unit of analysis in the LEHD data is a job, which is a relationship between an individual and an employer. We say that an individual $i$ is employed at employer $j$ in time $t$ if the worker received positive wages $w$ from that employer in quarter $t$. Formally:

$$
m_{i j t}=\left\{\begin{array}{l}
1, \text { if } w_{i j t}>0 \\
0, \text { otherwise }
\end{array}\right.
$$

A significant hurdle to precisely linking job histories in the LEHD data is the lack of start and end dates in state UI wage records - we are unable to determine the exact timing of when jobs begin and end. Because of this limitation, we restrict our job-to-job linkage to main jobs held on first day of the quarter. Specifically, an individual $i$ is beginning-of- 
quarter employed (what we will call B-employed herein) at employer $j$ in time $t$ if the worker received positive wages from that employer in both $t$ and $t-1$. Formally:

$$
b_{i j t}=\left\{\begin{array}{c}
1, \text { if } w_{i j t}>0 \text { and } w_{i j t-1}>0 \\
0, \text { otherwise }
\end{array}\right.
$$

The dominant (or main) beginning-of-quarter job domb $_{i j t}$ is the beginning-of-quarter job with the greatest combined wages across quarters $t$ and $t-1$, or:

$$
d o m b_{i j t}=\left\{\begin{array}{c}
1, \text { if } b_{i j t}=1 \text { and } w_{i j t}+w_{i j t-1}>w_{i l t}+w_{i l t-1} \forall b_{i l t} \text { where } l \neq j \\
0, \text { otherwise }
\end{array}\right.
$$

With these definitions, we define a series of relationships between dominant employers: origin employer $j$ and destination employer $k$, where the origin employer is a dominant B-employer in quarter $t$ and the destination employer is a dominant B-employer in either the subsequent quarter $t+1$, or (in the case of an intervening spell of nonemployment) another future quarter. This approach allows us to uniquely link the main job held on the first day of the quarter to the main job held at the start of the subsequent quarter. It does, however, have the obvious disadvantage of dropping job transitions between short duration jobs during the quarter. Thus this categorization restricts each worker to have only one job flow per quarter. ${ }^{2}$

A separation ${ }^{3}$ from the main job is identified as occurring during the quarter if no earnings for the main job are observed in the subsequent quarter. Specifically, we define transitions (any transition, whether to another job in the same quarter, the next quarter or to some nonemployment, hence all) among dominant beginning of quarter jobs (i.e., two consecutive quarters, hence 2) that involve a separation at the origin employer $j$, as follows:

$$
\text { all_doms } 2_{i j t}=\left\{\begin{array}{c}
1, \text { if } \operatorname{dom} b_{i j t}=1 \text { and } m_{i j t+1}=0 \\
0, \text { otherwise }
\end{array}\right.
$$

Likewise, new main job hires are accessions in this quarter to jobs that are the main job at employer $k$ held on the first day of the subsequent quarter:

$$
\text { all_doma } 2_{i k t}=\left\{\begin{array}{c}
1, \text { if } d o m b_{i k t+1}=1 \text { and } m_{i k t-1}=0 \\
0, \text { otherwise }
\end{array}\right.
$$

\footnotetext{
${ }^{2}$ While this approach is necessary given the limitations of the administrative data, a potential advantage of linking only main job-to-job transitions is that otherwise the job-to-job flows data would be dominated by transitions between very short transitory jobs that may not necessarily be economically interesting. Bjelland, et al. (2011) found that treating all very short duration jobs in the LEHD data as job-to-job flows resulted in an extremely high job-to-job flows rate - several times the implied CPS quarterly job-to-job flow rate. They speculate that a good many of these short jobs are likely held simultaneously - but it may be that there are simply a very large number of very transitory job transitions in the administrative data.

${ }^{3}$ The hires and separations associated with transitions of jobs that are dominant among beginning of quarter jobs is a subset of total hires and separations. Hyatt and Spletzer (2013) show that less than half of all hires and separations are associated with dominant job transitions, the remainder are associated with secondary or short-duration jobs.
} 
If a main job held on the first day of the quarter ends and a new main job starts within the same quarter, we call this a within-quarter job-to-job (employer-to-employer) flow.

$$
e e_{i j k t}=\left\{\begin{array}{c}
1, \text { if } a l l_{-} d o m s 2_{i j t}=1 \text { and } \text { all_doma } 2_{i k t}=1 \\
0, \text { otherwise }
\end{array}\right.
$$

Of course, even when the job separation and accession occur in the same quarter, there could be a spell of nonemployment between jobs. Such a spell would not necessarily be inconsistent with a voluntary job move - workers may choose to take a break between jobs. We simply cannot easily tell whether there was an intervening nonemployment spell between jobs. However, previous research linking jobs in the LEHD data strongly suggests that within-quarter job-to-job flows are largely voluntary job changes. First, within-quarter flows are highly procyclical. Second, earnings changes associated with these flows are strongly positive, with the median within-quarter job changer experiencing about 8\% earnings increase on average over the period 1998-2010, see Hyatt and McEntarfer (2012b). For these transitions, tenure, on average, is also longer at the destination job than the origin job, see Bjelland et al. (2011).

Turning to job separations and hires where a nonemployment spell between jobs can be identified, we differentiate between those with short and longer nonemployment spells. Main job separations to a new job in the next quarter (adjacent-quarter $a q$ flows) are identified as follows:

$$
a q_{-} d o m s 2_{i j t}=\left\{\begin{array}{c}
1, \text { if all_doms } 2_{i j t}=1 \text { and } a l l_{-} d o m a 2_{i k t+1}=1 \text { and } b_{i l t+1}=0 \forall l \\
0, \text { otherwise }
\end{array}\right.
$$

Thus, adjacent quarter job-to-job flows imply that an individual was employed at the beginning of quarter $t$, not employed at the beginning of quarter $t+1$, but is employed at the beginning of quarter $t+2$. To identify cases in which a transition involves nonemployment at the beginning $t+1$ and $t+2$, we introduce the notion of "persistent" nonemployment. Job separations and accessions from and to longer and more persistent spells of nonemployment (employment-to-nonemployment en2) are defined as follows, respectively:

$$
\text { en } 2_{-} \text {doms } 2_{\mathrm{ijt}}=\left\{\begin{array}{c}
1, \text { if all_doms } 2_{i j t}=1 \text { and } b_{i l t+1}=0 \text { and } b_{i l t+2}=0 \forall l \\
0, \text { otherwise }
\end{array}\right.
$$

and

$$
n e 2_{-} d o m a 2_{\mathrm{ikt}}=\left\{\begin{array}{c}
1, \text { if } a l l \_d o m a 2_{i k t}=1 \text { and } b_{i l t}=0 \text { and } b_{i l t-1}=0 \forall l \\
0, \text { otherwise }
\end{array}\right.
$$

Most of the persistently nonemployed are nonemployed for the entire quarter after separating or before starting their new job. But there may be other jobs in the preceding or subsequent quarter that do not span two quarters. Approximately $90 \%$ of all hires from and separations to persistent nonemployment have no earnings observed in the preceding or subsequent quarter (i.e., the hire is from or to full-quarter nonemployment), respectively. For those interested in these workers particularly, transitions to/from fullquarter nonemployment are provided as separate tabulation variables. 
While separations to (and hires from) persistent nonemployment are clearly distinct from within-quarter job-to-job flows, there is some ambiguity as to whether adjacent quarter job transitions are more correctly grouped with separations to persistent nonemployment in a single 'separations to (and hires from) nonemployment' category, or rather with within-quarter job-to-job flows, some of which also have a short nonemployment spell. While we tabulate them separately and leave this decision to the individual analyst, our preference is to classify adjacent-quarter flows with within-quarter job-to-job flows as predominantly voluntary job transitions. Like within-quarter flows, adjacent quarter flows are procyclical; they are also associated with positive earnings changes, see Hyatt and McEntarfer (2012b).

To calculate earnings changes associated with job change, we restrict attention to job transitions where both the origin and destination job have a full-quarter of earnings observed. An individual $i$ is full-quarter employed at employer $j$ in time $t$ if the worker received positive wages from that employer in periods $t-1, t$, and $t+1$. Formally:

$$
f_{i j t}=\left\{\begin{array}{c}
1, \text { if } w_{i j t-1}>0 \text { and } w_{i j t}>0 \text { and } w_{i j t+1}>0 \\
0, \text { otherwise }
\end{array}\right.
$$

Full-quarter to full-quarter job transitions can be written as

$$
f e e_{i j k t}=\left\{\begin{array}{c}
1, \text { if all_doms } 2_{i j t}=1 \text { and all_doma } 2_{i k t}=1 \\
\text { and } f_{i j t-1}=1 \text { and } f_{i k t+1}=1 \\
0, \text { otherwise }
\end{array}\right.
$$

Origin and destination job earnings are as follows:

$$
\begin{aligned}
& \text { fee_origearn }_{i j t}=w_{i j t-1}, \text { where } f e e_{i j k t}=1 \\
& f e e_{-} \text {destearn } n_{i k t}=w_{i k t+1}, \text { where } f e e_{i j k t}=1
\end{aligned}
$$

\section{Job-to-Job Flows Initial Release}

Figure 1 shows the J2J national job separation and accession rates for the United States, by whether the hire (or separation) is a flow from a recent employment spell or from a persistent nonemployment spell, for the period 2000-2011. ${ }^{4}$ The job-to-job hire and separation rates shown aggregate within-quarter and adjacent-quarter job transitions. Hires to and separations from persistent nonemployment are defined as in the previous section. This decomposition shows several interesting trends in labor market flows during the last decade. First, as noted by Hyatt and McEntarfer (2012a, 2012b) and Lazear and Spletzer (2012), there is a marked decline in the rate of job change over this period, particularly pronounced in the last two recessions. While there is also a slight downward

\footnotetext{
${ }^{4}$ The rates shown do not yet include adjustments to the national rates to account for a handful of LEHD states that are missing data early in the time series. This missing data imputation methodology is described in a later section of this paper and will be included in the first public release of the data, but was not ready at the time of this article. The bias in the national rates series caused by missing states is very small after 2000, see Henderson and Hyatt (2012).
} 
trend in hires to and separations from nonemployment, the recent decline in job separations and hires is largely driven by this decline in worker reallocation. ${ }^{5}$

In the national aggregate flows shown in Figure 1, job separations and hires from employment cancel each other out, and net employment flows are entirely due to flows to and from nonemployment. However, this will not be the case when net employment growth is decomposed at the industry or state-level. At the sub-national level, employment growth can occur because a state is 'poaching' employed workers from other states; industry growth can occur when an expanding industry poaches workers away from other industries.

The initial release of the J2J flows data will include job transition and flows to and from nonemployment at the national and state level, by industry sector, firm age and size, worker age, sex, education, and race/ethnicity. A powerful advantage of the LEHD data is that the size of the data allows even more detailed tabulations than these listed; later releases will likely include more detailed geography (metro area) and more detailed industry (industry sub-sector).

In addition to the rates series shown in Figure 1, the J2J data will also include origindestination statistics for flows from one job to another. Specifically, for job transitions that take place either within the quarter or within adjacent quarters, we tabulate characteristics of the origin and destination jobs - industry, geography, firm age and size. This allows a further decomposition of the data and a new set of statistics on labor market adjustment. For example, when decomposing the net employment decline of an industry into separations to employment and nonemployment, the separations to employment can further be stratified by destination industries and geographies. The published tabulations can therefore be used to measure the extent to which workers exiting a declining regional industry migrate somewhere else in the U.S. (which is beyond the scope of the CPS, which does not track movers) - and, in addition, the J2J data permits the measurement of associated earnings losses or gains associated with such transitions.

\section{Comparability to Other Data}

With any new data series, it is often instructive to compare it where we can with similar data. With regard to J2J flows to and from employment, the most comparable statistic is the employer-to-employer flows series constructed from the CPS by Fallick and Fleischman (2004). Fallick and Fleishman exploit the dependent interviewing technique adopted in the 1994 CPS redesign to identify workers who changed employers from one month to another. Since the Fallick and Fleischman CPS data is monthly, we simply sum the monthly data to obtain the quarterly rates, following Hyatt and Spletzer (2013). Note that individuals can have multiple employment transitions per quarter in the monthly Fallick and Fleishman series, while the LEHD J2J series limits workers to one job transition per quarter.

In Figure 2, we show a quarterly version of the CPS monthly rate of job-to-job flows along with the LEHD J2J series for job-to-job flows rates, one version that combines within and adjacent quarter transitions and another that restricts to flows where the

\footnotetext{
${ }^{5}$ Hyatt and Spletzer (2013) investigate several possible causes of the decline in employment dynamics during this period and find that relatively little of the decline can be explained by changes in worker demographics or industry composition over this period. Most of the decline in job change remains unexplained.
} 
separation and accession occurred within the same quarter. While there is a level difference in the rates, the trends between the two series track each other well: the CPS series has a correlation of 0.93 with the series that combines within- and adjacent-quarter flows, and a correlation of 0.89 with the within-quarter series. ${ }^{6}$ That the quarterly J2J jobto-job flow rate is lower than the CPS rate is expected - J2J links only main jobs held on the start and end of the quarter so workers that had several job changes during the quarter are counted only once.

Figure 3 compares the Fallick and Fleischman (2004) nonemployment inflows and outflows series to J2J flows to and from nonemployment. Again, the CPS rates are higher than those derived from the LEHD data. The CPS and LEHD data sources show small trends which diverge somewhat, especially during the expansion period between the two recessions. Although the levels are different and the overall trends diverge slightly, the series still move together on a quarterly basis: a correlation of 0.71 for separations and 0.82 for hires.

Figure 4 compares J2J separations to employment and persistent nonemployment to the quits and layoffs series in the Job Openings and Labor Turnover Survey (JOLTS). The correlation between JOLTS quits and LEHD J2J's version of job-to-job flows is quite high, at 0.98, and the correlation between JOLTS layoffs and J2J separations to persistent nonemployment is 0.61 . There is, however, a substantial level difference, with separations to persistent nonemployment being much higher in the J2J series. Davis, Faberman, Haltiwanger, and Rucker (2010) create a synthetic JOLTS layoff series adjusting for higher non-response rates in JOLTS from declining establishments; this adjusted layoffs series is higher than the J2J separations to persistent nonemployment rate, suggesting that the gap between the two series is largely due to establishments with larger employment declines being underrepresented in JOLTS.

\section{Disclosure Protection}

To ensure the confidentiality of the released data, the J2J flows will utilize a variety of confidentiality protection measures. In an extension of the existing noise infusion procedure used for the Quarterly Workforce Indicators (QWI), each item in the J2J data will receive a multiplicative fuzz factor, see Abowd et al. (2009). However, unlike the QWI, a particular feature of the J2J data is that many indicators involve flows between jobs. For transitions between employers, the noise infusion mechanism must consider whether to assign the fuzz factor associated with the origin establishment or the destination establishment. Our chosen methodology is based on the notion of an "edge" in graph theory and is designed to draw one fuzz factor from the two available, designating the chosen establishment fuzz factor as the fuzz factor for that edge. The new edge fuzz factor is used in all subsequent statistics and tabulations to multiplicatively modify any employment transition between the same two establishments.

In addition to noise infusion, the data product provides additional protection by synthesizing the values for small cells. Every quarter for each release table, we count the number of fuzzed zeros (n0), ones (n1), twos (n2), and threes (n3) in the cells that would otherwise be suppressed. To synthesize the values in these cells, we take a Bayesian

\footnotetext{
${ }^{6}$ The chief exception is a pre-recession collapse in the CPS job-to-job flows series around early 2007 with no corresponding decrease in the J2J rates. This decline in the CPS rate coincides with a sudden substantial increase in the missingness rate in the CPS on questions related to whether the respondent is still with the same employer as the last interview.
} 
approach by sampling from a multinomial Posterior Predictive Distribution (PPD). We use a uniform prior of size $\mathrm{U}$, and add the fuzzed counts to this prior, resulting in parameters for the Dirichlet posterior of $(n 0+U / 4, n 1+U / 4, n 2+U / 4, n 3+U / 4)$. To complete the table, we sample from the multinomial PPD once for each candidate suppressed cell, replacing what would have been a suppression with a synthesized value. The share of small cells is quite large in some tables and this approach enables the public release of complete tables while retaining confidentiality protection.

\section{Imputation of National Count Series}

Different states have provided data to the LEHD program with different start quarters. To avoid releasing primarily imputed data, we begin our time series in the second quarter of the year 2000. In the initial quarter, data is available for 41 states, with additional states becoming available in subsequent quarters. The last state to report is Massachusetts, which is missing data for the first 41 quarters of the release. By 2010Q2 the data is complete, with all 50 states and the District of Columbia reporting regularly to LEHD.

In the first quarter of the planned release, the states with complete data make up about 87\% of QCEW 2012Q2 Month1 private sector employment. As shown in Figure 5 below, the proportion of total employment covered by the data grows as new states enter the LEHD production system. The largest state with missing data, Michigan, enters first, followed by an almost equal sized cluster of three geographically dispersed states. Another five states appear over the next four years and by 2005Q2 the data is virtually complete except for Massachusetts which does not appear in the data for another five years (2010Q2).

To deal with the missing data issue we use the method proposed and implemented for the QWI by Abowd and Vilhuber (2011). We develop two missing data models, the first covers the period prior to 2005Q2 and the second model covers the later missing data period. The Abowd and Vilhuber (2011) approach imputes the time series for the missing data states assuming the rates are missing at random (ignorable) conditional on various characteristics of the worker and the firm. We maintain this assumption in our implementation, but we also address a fundamental difference in the data required to calculate unbiased J2J statistics.

For the QWI, the statistics are unbiased at the state level when other states are missing; however, this is not the case for the J2J flows. The J2J flows use the concept of a national dominant job for each worker each quarter; if data for a state is missing, a non-dominant job in a reporting state may be incorrectly classified as dominant job. In addition, workers that transition to a job in a missing data state will be incorrectly classified as transitioning to nonemployment. To address the resulting bias in the rates for the complete data states, we adjust them using information from 2010Q2 forward where all of the states are available. We then sample from the adjusted rates using the method proposed by Abowd and Vilhuber (2011). With the data completed, the national rate estimates and standard errors are formed using the customary Rubin (1987) combining formulas, properly accounting for the additional uncertainty due to both the missing state data as well as the rate adjustment process. 


\section{Conclusion}

A public-use data product on employer-to-employer flows is one of the remaining gaps in the federal statistical system in the United States. In this paper, we have demonstrated the promise of administrative records for the creation of these data. Specifically, we have outlined the strategy of the U.S. Census Bureau's LEHD program for the production of new data on job-to-job flows. Preliminary output data is strongly correlated with similar series derived from two widely known data sources, the CPS and the JOLTS.

\section{References}

Abowd, John M. Haltiwanger, John C., and Lane, Julia I., 2004. “Integrated Longitudinal Employee-Employer Data for the United States”, American Economic Review: Papers \& Proceedings 2004, 94(2): 224-229.

Abowd, John M., Bryce E. Stephens, Lars Vilhuber, Fredrik Andersson, Kevin L. McKinney, Marc Roemer, and Simon D. Woodcock. 2009. "The LEHD Infrastructure Files and the Creation of the Quarterly Workforce Indicators.” In Producer Dynamics: New Evidence from Micro Data, Vol. 68, Studies in Income and Wealth, ed. Timothy Dunne, J.Bradford Jensen and Mark J. Roberts, 149-230. Chicago: University of Chicago Press.

Abowd, John M. and Lars Vilhuber. 2011 "National estimates of gross employment and jobs flows from the quarterly workforce indicators with demographic and industry detail”, Journal of Econometrics, 161, 82-99.

Bjelland, Melissa, Bruce Fallick, John Haltiwanger and Erika McEntarfer. 2011. "Employer-to-Employer Flows in the United States: Estimates Using Linked EmployerEmployee Data.” Journal of Business and Economic Statistics, 29(4): 493-505.

Davis, Steven, Jason Faberman, John Haltiwanger, and Ian Rucker. 2010. "Adjusted Estimates of Worker Flows and Job Openings in JOLTS." In Labor in the New Economy, Vol. 71, Studies in Income and Wealth, ed. Katharine Abraham, James Spletzer, and Michael Harper, 187-216. Chicago: University of Chicago Press.

Fallick, Bruce, and Charles Fleischman. 2004. "Employer-to-Employer Flows in the U.S. Labor Market: The Complete Picture of Gross Worker Flows.” Federal Reserve Board Finance and Economics Discussion Series Working Paper 2004-34.

Fallick, Bruce, John Haltiwanger, and Erika McEntarfer. 2012. "Job-to-Job Flows and the Consequences of Job Separations." Federal Reserve Board Finance and Economics Discussion Series Working Paper \#2012-73.

Haltiwanger, John, Henry Hyatt, Erika McEntarfer, Liliana Sousa, and Stephen Tibbets. 2014. "Firm Age and Size In the Longitudinal Employer-Household Dynamics Data" Center for Economic Studies Discussion Paper CES-14-16.

Henderson, Cody, and Henry R. Hyatt. 2012. "Estimation of Job-to-Job Flow Rates Under Partially Missing Geography." Center for Economic Studies Discussion Paper CES-12-29. 
Hyatt, Henry, and Erika McEntarfer. 2012a. “Job-to-Job Flows in the Great Recession” American Economic Review: Papers \& Proceedings 2012, 102(3): 580-583.

Hyatt, Henry, and Erika McEntarfer. 2012b. "Job-to-Job Flows and the Business Cycle.” Center for Economic Studies Working Paper \#12-04, U.S. Census Bureau.

Hyatt, Henry, and James Spletzer. 2013. "The Recent Decline in Employment Dynamics.” IZA Journal of Labor Economics 2(5): 1-21.

Lazear, Edward, and James Spletzer. 2012. "Hiring, Churn, and the Business Cycle." American Economic Review: Papers \& Proceedings 2012, 102(3): 575-579.

Rubin, Donald. 1987. Multiple Imputation for Nonresponse in Surveys. New York: Wiley. 
Figure 1: Hires and Separations: Job Change vs. Nonemployment

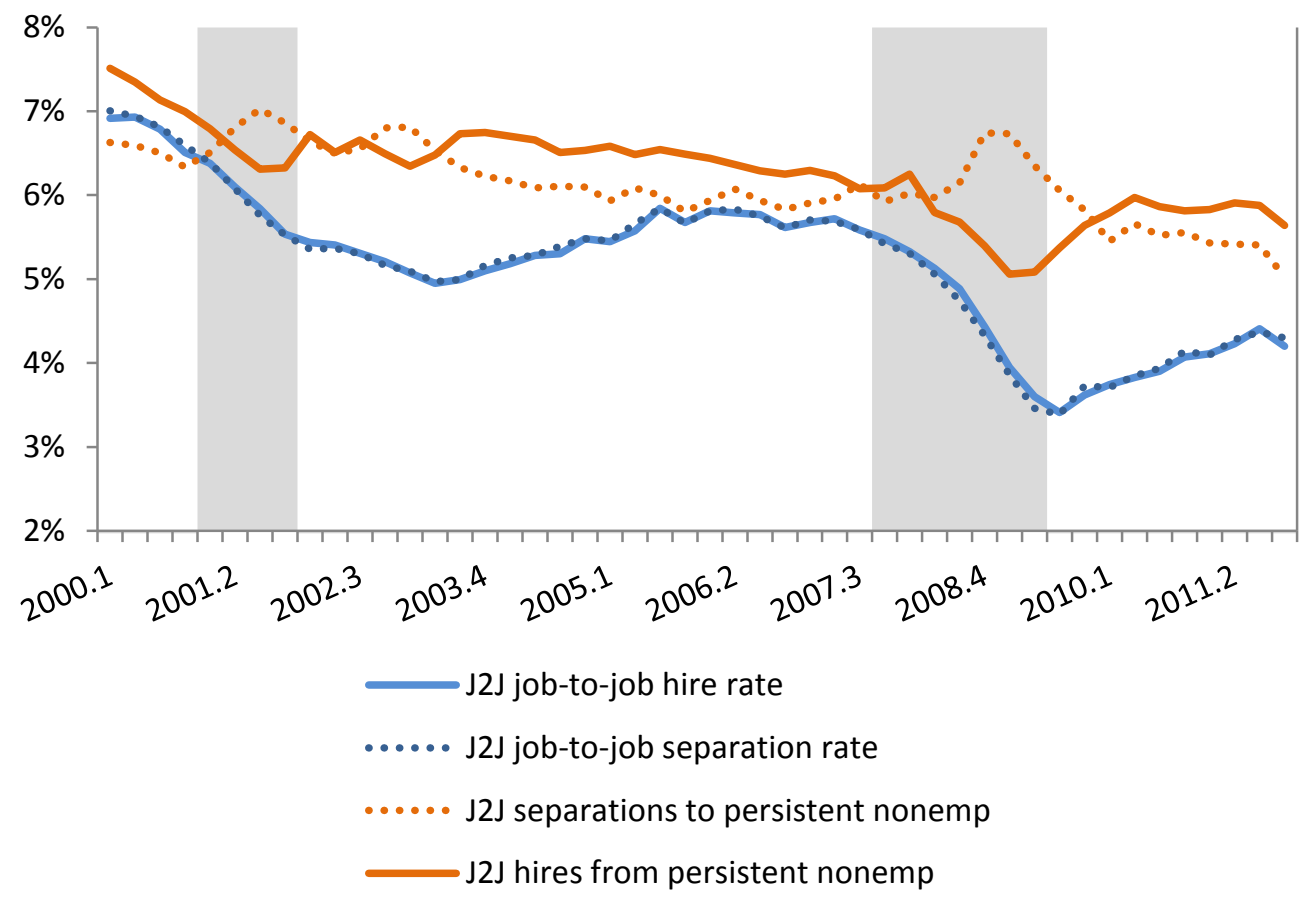

Note: Shaded regions indicate NBER recession quarters. All data are seasonally adjusted. These J2J tabulations do not include planned adjustments to the J2J series to account for partially-missing geography early in the time series. J2J job-to-job hires are new main job starts this quarter where the separation from the previous main job occurred either in this quarter or the previous quarter. Job-to-job separations are separations from main jobs associated with a new job start this quarter or the subsequent quarter. Separations to persistent nonemployment are nonemployed both at the end of the quarter and the end of the subsequent quarter. Accessions from persistent nonemployment are not employed at this start of this quarter as well as the start of the previous quarter. Approximately $90 \%$ of the persistently not employed had zero earnings in the quarter prior/subsequent to the job start/separation. 
Figure 2: Comparison of LEHD and CPS Job-to-Job Flows

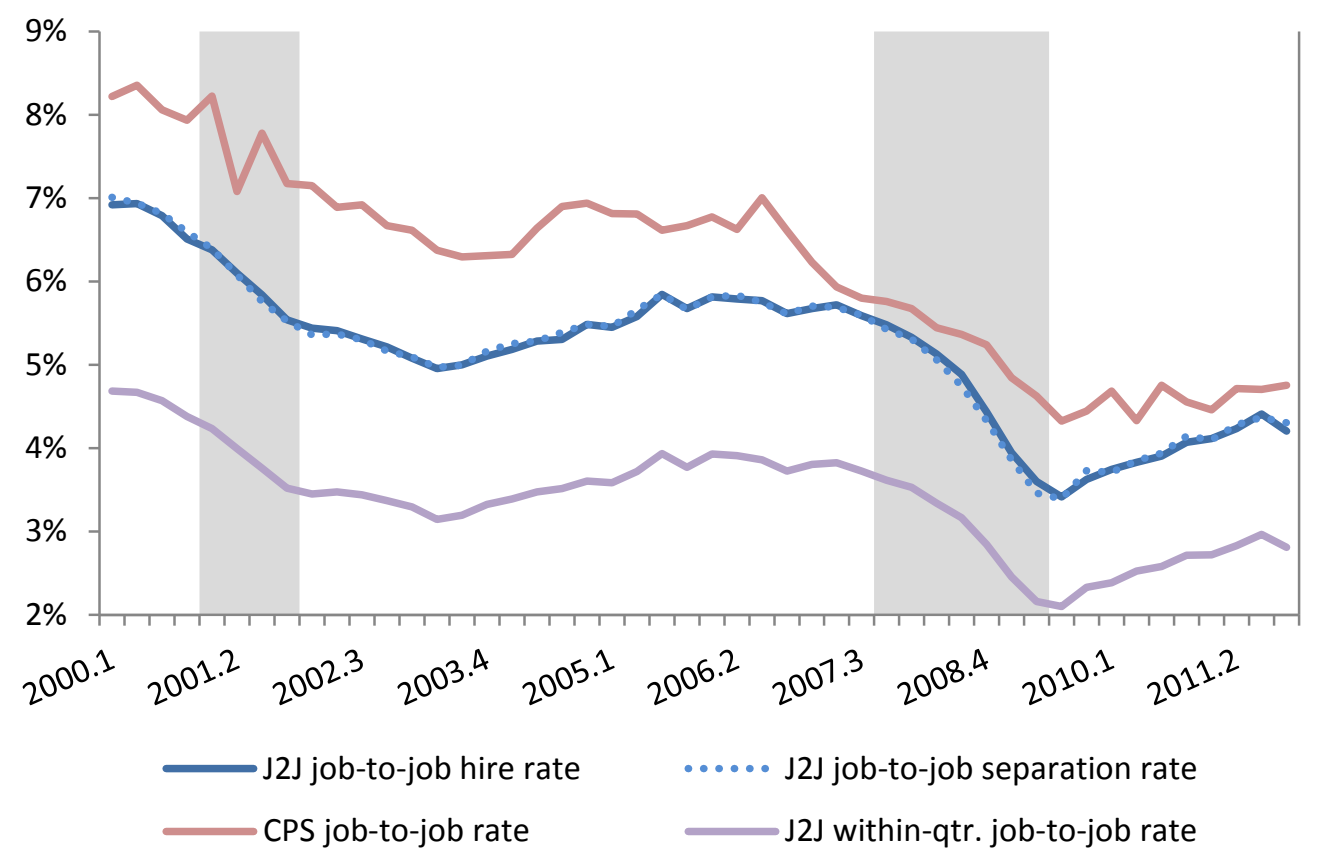

Note: Shaded regions indicate NBER recession quarters. All data are seasonally adjusted. These J2J tabulations do not include planned adjustments to the J2J series to account for partially-missing geography early in the time series. CPS job-to-job flows series is calculated from the CPS by Fallick and Fleischman (2004). J2J hire rate here refers to new main job starts this quarter where the separation from the previous main job occurred either in this quarter or the previous quarter. J2J separations are separations from main jobs associated with a new job start this quarter or the subsequent quarter. The within-qtr. job-to-job flow rate restricts the J2J flows to starts and separations that occur within the same quarter only. 
Figure 3: Comparison of LEHD and CPS Flows to and from Nonemployment

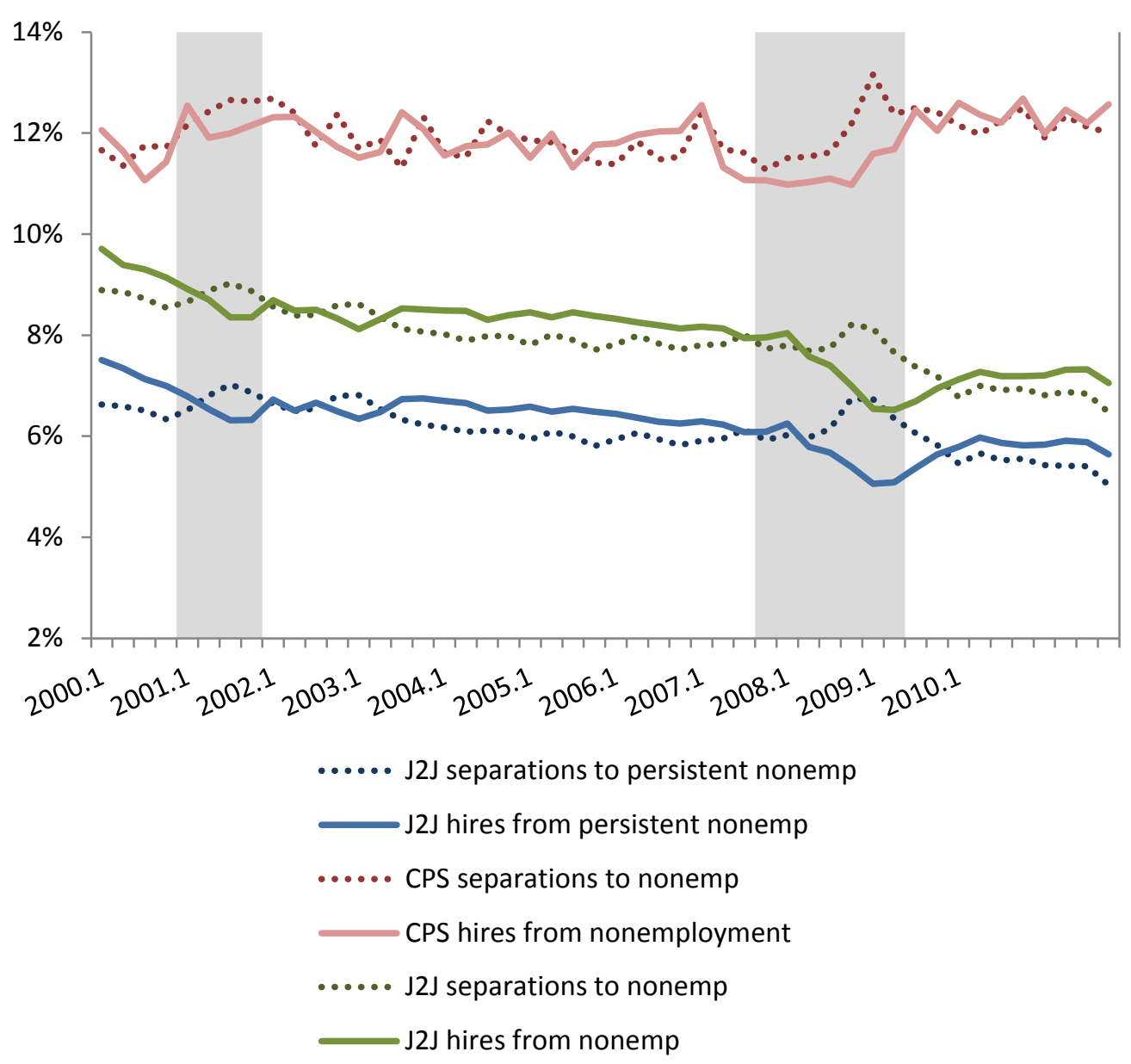

Note: Shaded regions indicate NBER recession quarters. All data are seasonally adjusted. These J2J tabulations do not include planned adjustments to the J2J series to account for partially-missing geography early in the time series. CPS data was downloaded from the Fallick and Fleischman (2004) website. J2J hires/separations from nonemployment includes adjacent-quarter job-to-job flows as well as flows from persistent nonemployment. 
Figure 4: Comparing J2J Separations to Quits and Layoffs from JOLTS

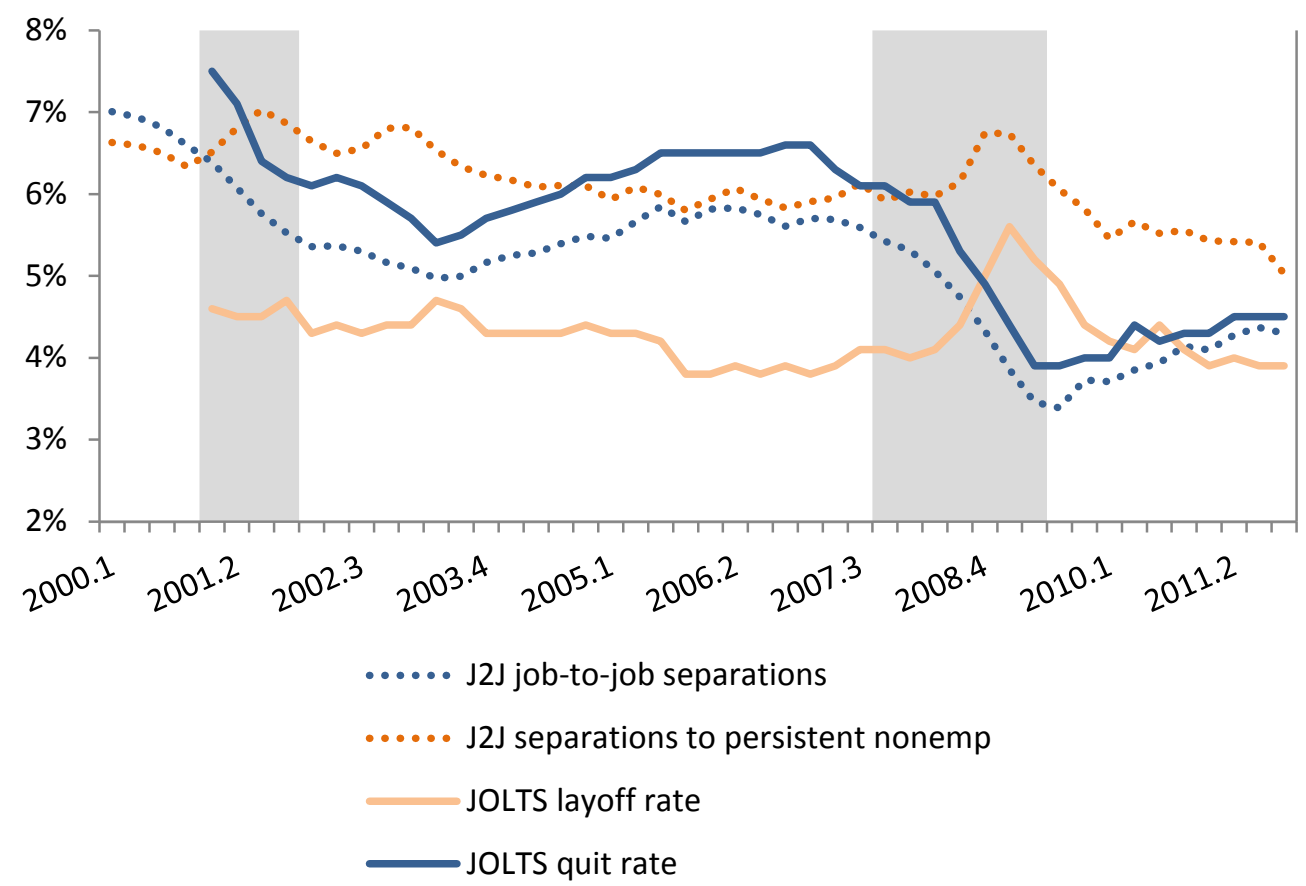

Note: Shaded regions indicate NBER recession quarters. All data are seasonally adjusted. These J2J tabulations do not include planned adjustments to the J2J series to account for partially-missing geography early in the time series. JOLTS data are from the BLS website. J2J job-to-job separations are separations from main jobs associated with a new job start this quarter or the subsequent quarter. Separations to persistent nonemployment are nonemployed both at the end of the quarter and the end of the subsequent quarter. 
Figure 5: Proportion of Private Sector Employment for States in LEHD

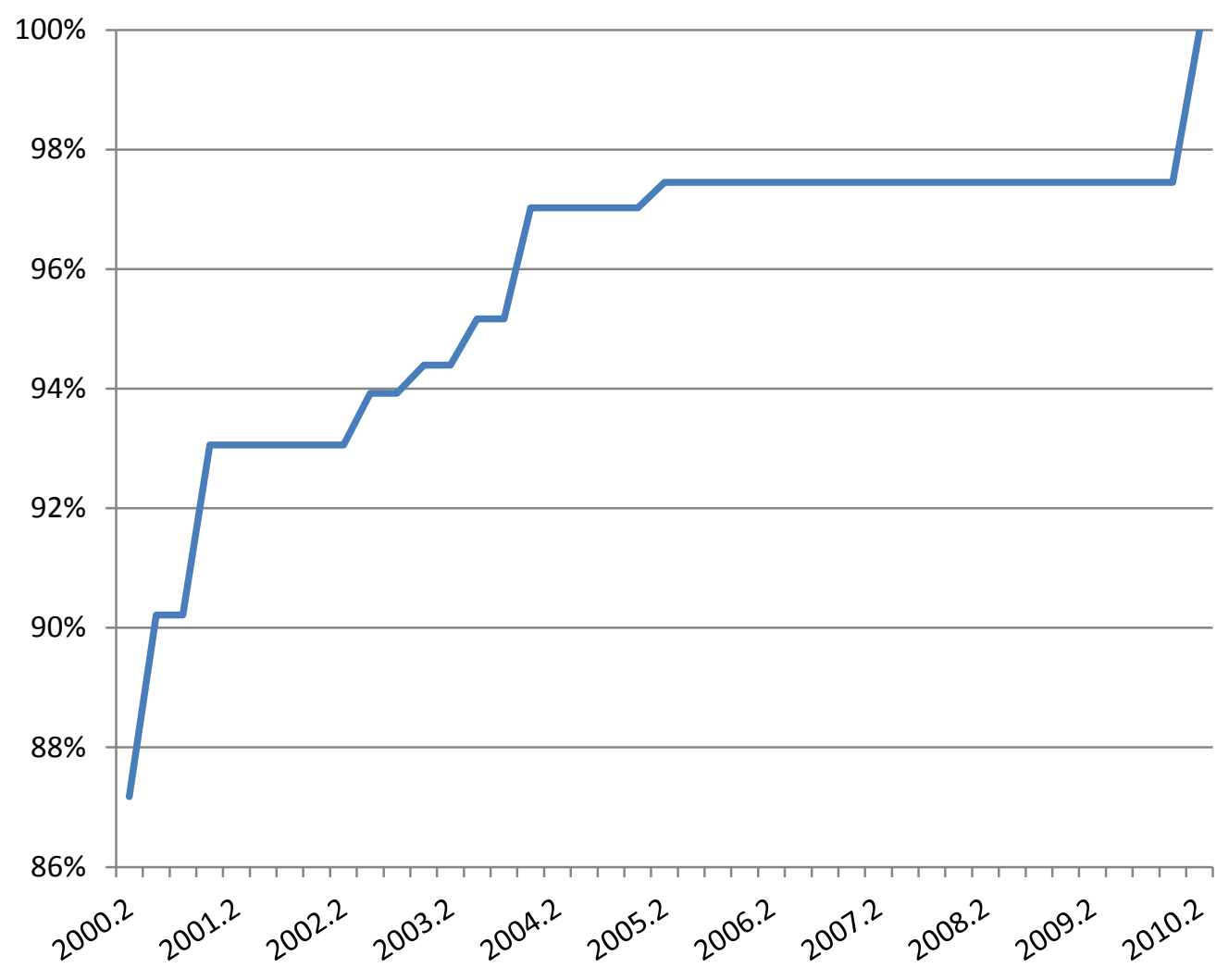

Note: Shares of QCEW private sector employment totals for April of 2012 as downloaded from the BLS website. Coverage reflects the number of states with data that has passed quality assurance thresholds for release in the QWI. 